\title{
Exploring the Relationship between IT Infrastructure and Income Inequality through Diffusion of Innovations Theory
}

\author{
David Kocsis, Ph.D. \\ University of Colorado - Colorado Springs \\ dkocsis@uccs.edu
}

\begin{abstract}
Some cities in the United States experience gaps when it comes to income inequality. Entrepreneurs, managers, etc. can take advantage of information technologies (IT), while those in the middle and the bottom see fewer benefits. San Francisco is a perfect example of this dichotomy. Meanwhile, some countries, such as Iceland, are more capable of using the diffusion of Internet infrastructure to reduce income inequality, which contributes to the wellbeing of its citizens. This paper explores the relationship between the diffusion of IT infrastructure and income inequality through Rogers's Diffusion of Innovations Theory. Using quantitative data through hierarchical regression, the empirical results show this theory's tenets do not necessarily hold, because there is a significant negative relationship between infrastructure diffusion and income inequality growth. This paper contributes to research by expanding economic and sociology work to the IS domain, and provides suggestions for practice, such as more focused IT infrastructure investments.
\end{abstract}

\section{Introduction}

The podcast Zig Zag explores issues related to economics, capitalism, and technology. Producer Manoush Zomorodi lives in New York but was in San Francisco for a project - the first thing she noticed was the inequality between the conference center and the streets [1]. She wondered how such a booming city like San Francisco can have so much inequality.

A robust information infrastructure may create access to online services for everyone, bridge the digital divide, and create jobs [2]. Despite the benefits, American cities with incredible innovation and infrastructure, such as San Francisco, the income inequality appears to increase. The individuals in the middle and top receive all the benefits, while those at the bottom appear incapable of reaping the benefits
[3]. This inequality may stem from many issues, so this research focuses on infrastructure availability and its relationship to income inequality.

Rogers theorized as diffusion of innovations increase, communities may experience an increase in social and income inequality [4]. Cities like San Francisco reflect this theory on the surface. To explore whether information technology (IT) innovations and infrastructure increase inequality, this research aims to answer two questions. First, does a growth in a country's information infrastructure lead to a growth in income inequality? Second, what is the relationship between infrastructure and income inequality within the United States?

The paper proceeds as follows to answer these questions. First, I summarize related research and present the hypotheses. Second, I outline the data analysis methods. Third, I present the results of the analysis. Fourth, I discuss the results in detail. The paper concludes with a summary of contributions, limitations, and with future research directions.

\section{Related Research and Hypotheses}

The related research for this paper focuses on three fundamental components: diffusion of innovations theory, income inequality, and the relationship between income inequality and diffusion of innovations.

\section{Diffusion of Innovations Theory}

The basis of diffusion innovations theory (DOI) stems from the work of sociologist Everett Rogers in 1962, who defined an innovation as "an idea, practice, or object that is perceived as new by an individual or other unit of adoption" [5]. Such innovations, for example the Internet, may affect individuals, organizations, and societies. Rogers identified five general attributes of innovations which consistently influence adoption: relative advantage, 
compatibility, complexity, observability, and trialability.

Diffusion in this context comprises four main elements, defined as "the process by which (1) an innovation (2) is communicated through certain channels (3) over time (4) among the members of a social system" [5]. The diffusion process tracks the four elements as a function of the percentage of adoption and time. Early in the implementation adoption comprises long periods of time. Once time reaches a midpoint, the adoption starts to take off, with a steep growth of adoption over a short time period, until the adoption tails off for the last 20-30\% of adopters. See Figure 1 for a visualization of this bell curve [4].

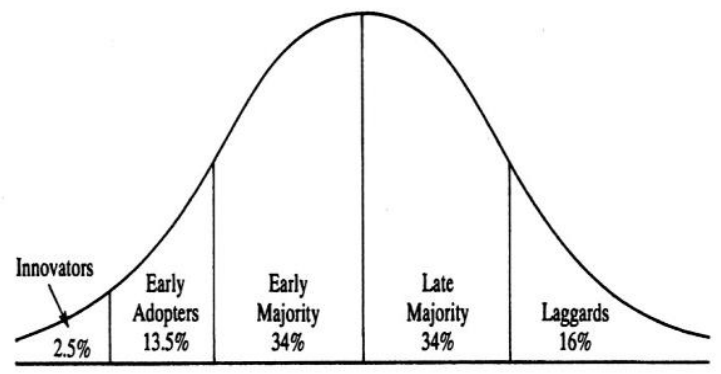

Figure 1. Rogers adopter categorization based on innovativeness

Diffusion of innovation theory remains pervasive across research disciplines and informing policy. Through the lens of DOI, innovation policies have the potential to make innovative technologies more widely available [6]. Broadband Internet access within countries often extends DOI. Key factors in broadband diffusion in Korea include government regulation and policy, cost and competition, and uncertainty [7].

Although diffusion of innovation theory originated in sociology, information systems (IS) research uses the theory extensively. While sociology research focuses on adoption and society, IS research focuses on IT adoption in organizations. DOI has influenced some of the most important IS research on adoption. Moore and Benbasat expanded the five general attributes of adoption to prescribe eight measures for the adoption and diffusion of innovations: relative advantage, compatibility, ease of use, result demonstrability, image, visibility, trialability, and voluntariness [8] (italicized measures are the new factors Moore and Benbasat identified). The Unified Theory of Acceptance and Use of Information Technology (UTAUT) uses complexity as a predictor of adoption and expands on the Moore and Benbasat measures to include perceptions of IT innovation adoption [9].

As DOI is a sociological theory, researchers must extend and integrate technology and innovation characteristics. The integrated diffusion model integrates DOI with technology-fit theory, finding compatibility, cost, relative advantage, and complexity, as well as communication, entertainment, and information tasks, as significant predictors on the intention to adopt personal information systems [10].

IS studies on Enterprise Resource Planning (ERP) adoption extends DOI into IS success at the enterprise level. Bradford and Florin used DOI to measure the relationship between DOI constructs, satisfaction, and organizational performance. They found complexity was a negative predictor of satisfaction, performance, and compatibility [11].

E-commerce and web technologies also extend DOI. Perceived benefits, compatibility, and complexity are all significant predictors of website adoption in organizational settings [12]. In Electronic Data Interchange implementations, relative adoptions, costs, and technical compatibility are significant predictors of diffusion [13]. Research on social media usage extends DOI into emerging and disruptive innovations. For instance, Miranda, Kim, and Summers used organizing vision theory, which argues community and coherence may be significant predictors of diffusion [14].

\section{Income Inequality}

Income inequality comprises many factors and definitions, with a generally accepted definition as the share of income within a locale (e.g., city, state, country, region, world) going to the top 1 percent or top 0.1 percent of earners [15].

Socio-economic inequality can manifest into many issues, such as lack of opportunity and a decrease in the subjective well-being of individuals [16]. Income inequality rose sharply in the United States (US) in the last forty years, but has increased only slightly in other countries such as France and Japan [15]. Reducing economic growth within a country may also be a negative outcome for countries (or cities, states, regions) with increased inequality. Within the United States, researchers found a negative relationship between income inequality and economic growth [17]. This negative relationship is not unique to the US - South America also 
experiences this negative relationship, such that as inequality increases, economic growth decreases [18].

The generally accepted measure of income inequality comes from the Gini index of income inequality. The Gini index varies from 0 (i.e., $0 \%$ ) to 1 (i.e., 100\%), with a 1 indicating perfect inequality and a 0 indicating perfect equality [19]. In other words, if the Gini index is lower, the equality is better. Many world organizations track the Gini coefficient such as the US census, CIA, the World Bank, and the World Economic Forum. The world Gini coefficient has decreased in recent years, from .80 in 1988 to .65 in 2013 [20], which indicates global inequality has decreased. However, some researchers have argued there has been a sharp rise in income inequality in the last few decades, especially in developed countries [21], although the underlying factors are uncertain. Income inequality in the United States grew more than $11 \%$ between 1979 and 2005 [22].

\section{Hypotheses}

The relationship between diffusion of innovations and income inequality is a fundamental principle of diffusion innovation theory. The diffusion of innovations often widens the gap between higher and lower income groups in a social system [5]. The United States experiences this gap, as a positive correlation exists between innovation and top income inequality across US states $[15,21]$.

In the context of IT infrastructures, researchers have used DOI and other theories to understand the link between Internet penetration and income inequality. Moreover, much research on the effects of Information and Communication Technologies (ICT) focus on economic growth rather than inequality [23]. Cross-nationally, the effect of ICTs on income inequality depends on the type of ICT (e.g., broadband, mobile), the measure of income inequality, and other economic and political factors [23]. Other measures of income inequality include the index of financial inclusion (IFI), and there is a positive relationship between the growth of Internet and telecommunication use and IFI [24].

Based on the above two paragraphs, I observe a mix of effects of innovation diffusion on income inequality. See Figure 1 for the research model.

Because this research focuses on DOI as a theoretical basis, this research hypothesizes that income inequality increases in relation to infrastructure diffusion:

H1: As diffusion of IT infrastructure innovations improves in a country, income inequality will increase.

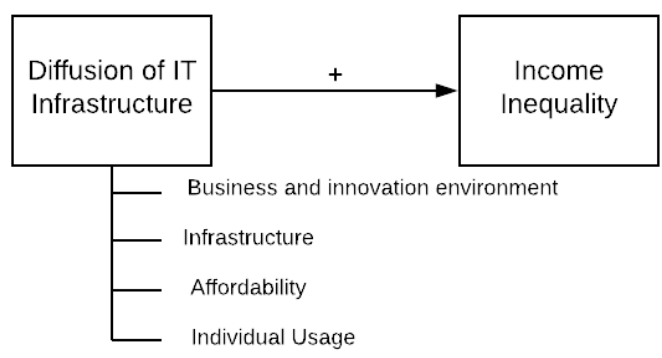

Figure 1. Research Model

The United States ranks among the top developed countries for Internet penetration and IT infrastructure. Unfortunately, the United States also ranks among the lowest developed countries regarding income inequality. As such, this research hypothesizes that income inequality declines in relation to infrastructure diffusion within the United States:

H2: As diffusion of IT infrastructure innovations improves in states in the US, income inequality will increase.

\section{Data Analysis Plan}

Hypothesis 1 assesses the relationship between IT infrastructure diffusion and income inequality by country. No single datasets exist with infrastructure diffusion and income inequality, so I obtained and combined data from multiple sources within the World Economic Forum (WEF). IT infrastructure diffusion data comes from the Global Information Technology Report for 2012-2016 [25]. Each IT usage characteristic rates on a continuous scale from 1 (e.g., no infrastructure) to 7 (e.g., perfect infrastructure). For example, Haiti has the worst infrastructure in the dataset (1.34), while Iceland has the best infrastructure (6.94). All other IT usage characteristics use the same continuous scale.

Income inequality data comes from the Inclusive Development Index for 2018 [26]. The WEF uses a net income Gini ranging from 0 (perfect equality) to 100 (perfect inequality). For example, the country with the highest inequality is South Africa (57.7), while Iceland has the highest equality (24.4). 
To test the hypothesis, I regressed the dependent variable (income inequality) on a series of IT usage characteristics (the independent variables): business and innovation environment, infrastructure, affordability, and individual usage. The reports contained complete data on 98 countries.

Hypothesis 2 assesses the relationship between IT infrastructure diffusion and income inequality in the United States. Again, there is no single dataset with infrastructure diffusion and income inequality, so I obtained and combined data from multiple sources for the year 2015 (the most recent year with both Gini data and infrastructure data). The income inequality Gini data comes from the US Census Bureau [19]. The Gini index falls on a continuous scale from 0 to 1 , where 0 indicates perfect equality, and 1 indicates perfect inequality. For example, the state with the highest inequality is New York (0.514), and the state with the highest equality is Utah (0.425).

Infrastructure data comes from the US News and World Report [27]. The report considers the percentage of households with broadband internet subscriptions along with the share of the state's population with access to high-speed broadband. The report then ranks the states from 1 to 50 . While the Census Bureau uses the Gini index, the World Report uses a ranking system. As such, I converted the Gini data to ranked data before regressing the income inequality ranking on Internet access ranking by state.

\section{Results}

This section details the data analysis results and hypothesis testing.

\section{Hypothesis 1}

All independent variables displayed a significant positive correlation with each other, while displaying a significant negative correlation with the dependent variable, income inequality. See the Pearson correlations in Table 1.

The descriptive statistics are in Table 2. Income inequality is on a scale from 0 to 100 , where 0 indicates perfect equality and 1 indicates perfect inequality. Each IT usage characteristic rates on a continuous scale from 1 (e.g., no infrastructure) to 7 (e.g., perfect infrastructure).
Table 1. Correlation Table

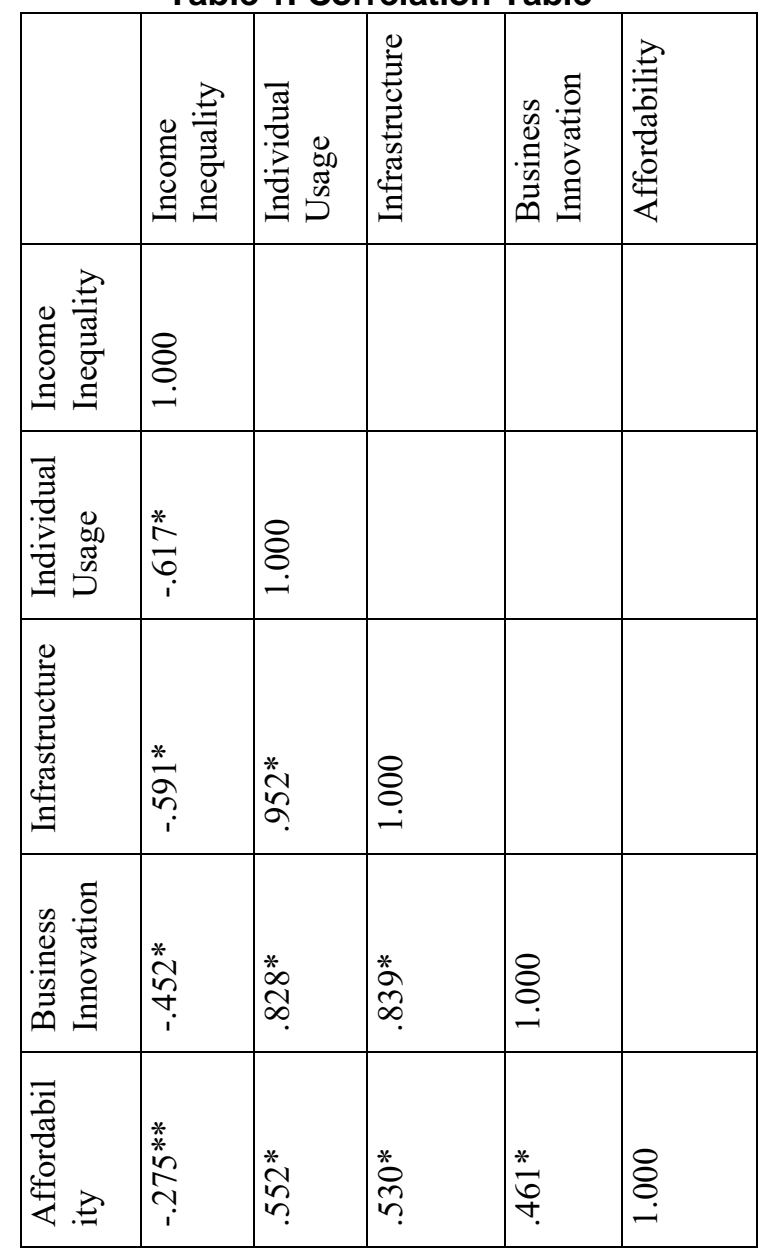

Note: $\mathrm{N}=95 ; * \mathrm{p}=.000 ; * * \mathrm{p}=.003$

Table 2. Descriptive Statistics

\begin{tabular}{|l|l|l|}
\hline & Mean & $\begin{array}{l}\text { Standard } \\
\text { Deviation }\end{array}$ \\
\hline $\begin{array}{l}\text { Income } \\
\text { Inequality }\end{array}$ & 37.33 & 7.63 \\
\hline Infrastructure & 4.23 & 1.48 \\
\hline $\begin{array}{l}\text { Business } \\
\text { Innovation }\end{array}$ & 4.30 & 0.61 \\
\hline Affordability & 5.15 & 1.14 \\
\hline $\begin{array}{l}\text { Individual } \\
\text { Usage }\end{array}$ & 3.89 & 1.51 \\
\hline
\end{tabular}

Note: $\mathrm{N}=95$

Next, I ran a hierarchical regression, entering one variable at a time. The first model regressed income inequality on individual usage, followed by affordability (model 2), business and innovation (model 3), and infrastructure (model 4). See Table 3 for the model summary. Each variable displayed a significant negative relationship with income inequality. 
Table 3. Regression Model Summary

\begin{tabular}{|c|c|c|c|c|c|}
\hline & Model & 1 & 2 & 3 & 4 \\
\hline & $\mathrm{R}$ & 0.617 & 0.622 & 0.63 & 0.632 \\
\hline & $\mathrm{R}^{2}$ & 0.380 & 0.387 & 0.397 & 0.399 \\
\hline & usted $\mathrm{R}^{2}$ & 0.374 & 0.373 & 0.377 & 0.372 \\
\hline & SE & 5.968 & 5.971 & 5.952 & 5.975 \\
\hline & $\begin{array}{c}\mathrm{R}^{2} \\
\text { Change }\end{array}$ & 0.380 & 0.006 & 0.011 & 0.002 \\
\hline 帘 & $\begin{array}{c}\mathrm{F} \\
\text { Change }\end{array}$ & 57.100 & 0.920 & 1.604 & 0.290 \\
\hline$\stackrel{n}{2}$ & df1 & 1 & 1 & 1 & 1 \\
\hline $\begin{array}{l}\vec{E} . \\
\text {. }\end{array}$ & $\mathrm{df} 2$ & 93 & 92 & 91 & 90 \\
\hline & $\begin{array}{l}\text { Sig. F } \\
\text { Change }\end{array}$ & 0.000 & 0.340 & 0.209 & 0.592 \\
\hline
\end{tabular}

Because none of the models increased the significance above and beyond the previous model, I regressed income inequality individually on each of the four independent variables. Each of the factors had a significant negative relationship with income inequality.

First, I regressed income inequality on individual usage, and the model showed a significant negative relationship, $F(1,96)=58.942, p=.000, R^{2}=.380 \beta$ $=-.617$. That is, individual usage significantly predicted income inequality, such that as individual usage increases, income inequality decreases. Individual usage accounted for $38.0 \%$ of the variance in income inequality.

Second, I regressed income inequality on affordability, and the model showed a significant negative relationship, $F(1,93)=7.617, p=.007, R^{2}=$ $.076, \beta=-.275$. That is, individual usage significantly predicted income inequality, such that as affordability increases, income inequality decreases. Affordability accounted for $7.6 \%$ of the variance in income inequality.

Third, I regressed income inequality on business innovation, and the model showed a significant negative relationship, $F(1,96)=24.706, p=.000, R^{2}$ $=.205, \beta=-.452$. That is, business innovation significantly predicted income inequality, such that as business innovation increases, income inequality decreases. Business innovation accounted for $20.5 \%$ of the variance in income inequality.

Fourth, I regressed income inequality on infrastructure, and the model showed a significant negative relationship, $F(1,96)=51.406, p=.000, R^{2}$
$=.349, \beta=-.591$. That is, infrastructure significantly predicted income inequality, such that as infrastructure increases, income inequality decreases. Infrastructure accounted for $34.9 \%$ of the variance in income inequality.

The significant relationships between IT diffusion factors appeared in the opposite direction of hypothesis 1 . As such, the evidence does not support hypothesis 1 .

\section{Hypothesis 2}

Hypothesis 2 explores the relationship between infrastructure diffusion and income inequality within states in the US. The initial correlation and regression induced surprising results. Internet access and inequality did not show a significant correlation $(r=$ .138). I then regressed inequality on Internet access, and the model showed a non-significant relationship, $F(1,48)=.930, p=.340, R^{2}=.019$. That is, Internet access by state did not significantly predict income inequality. Internet access only accounted for $1.9 \%$ of the variance in income inequality.

Upon this result, I observed high variance for each state in terms of Internet access and inequality. For instance, in some states like Alabama, they were among the lowest for both variables. However, Indiana was 42 in Internet access while ranking 12 in inequality. Many of the southern states seemed low in both factors, while states in the west seemed strong for both inequality and Internet access. I verified this empirically by categorizing the states into four regions: south, west, midwest, and east based on the US Census. The average rank of inequality in the south was 32.88 while Internet access was 31.69 . The average respective ranks for the east were 30.44 and $20.88,18.54$ and 16.00 in the west, and 18.25 and 25.58 in the midwest.

After this observation, I ran a hierarchical regression with two models. Model 1 regressed inequality on Internet access, while model 2 added region to the regression equation. The second model showed a significant relationship, $F(1,47)=10.501$, $p=.002, R^{2}=.198$. That is, region significantly predicted income inequality, such that as infrastructure increases in certain regions, income inequality increases. As such, the evidence partially supports hypothesis 2 . See Table 4 for a summary of the hypotheses. 
Table 4. Hypothesis Summary

\begin{tabular}{|c|c|c|}
\hline Hypothesis & Outcome & Comments \\
\hline $\begin{array}{l}\text { H1: As diffusion of } \\
\text { IT infrastructure } \\
\text { innovations } \\
\text { improves in } r \\
\text { country, a } \\
\text { inequality }\end{array}$ & $\begin{array}{l}\text { Not } \\
\text { Supported }\end{array}$ & $\begin{array}{ll}\text { As } & \text { IT } \\
\text { infrastructure } & \\
\text { improves } & \text { in } \\
\text { countries, } & \\
\text { income } & \\
\text { inequality } & \\
\text { significantly } & \\
\text { decreases. } & \end{array}$ \\
\hline $\begin{array}{l}\text { H2: As diffusion of } \\
\text { IT infrastructure } \\
\text { innovations } \\
\text { improves in states in } \\
\text { the US, income } \\
\text { inequality will } \\
\text { increase. }\end{array}$ & $\begin{array}{l}\text { Partially } \\
\text { Supported }\end{array}$ & $\begin{array}{l}\text { As IT } \\
\text { infrastructure } \\
\text { improves in } \\
\text { states, income } \\
\text { inequality does } \\
\text { not significantly } \\
\text { change. } \\
\text { However, within } \\
\text { regions, income } \\
\text { inequality does } \\
\text { significantly } \\
\text { increase. }\end{array}$ \\
\hline
\end{tabular}

\section{Discussion}

In this section, I discuss the results in more detail, limitations, and contributions. I start by discussing the global results, then the United States results regarding the relationship of IT infrastructures and income inequality. Diffusion of innovations theory provided the basis for the hypothesis development, but regarding the diffusion of the Internet and IT infrastructure, DOI theory does not hold.

\section{Global}

I used four factors as a function of IT infrastructure diffusion in countries - affordability, business innovation, individual usage, and infrastructure. All four factors correlated, so this section will focus on infrastructure and its relation to income inequality. The first hypothesis predicted an increase in infrastructure diffusions would lead to an increase in income inequality, as posited by DOI. However, I observed the opposite effect infrastructure diffusions lead to a decrease in income inequality. Using the logic of DOI, only individuals at the top of the income distribution will profit from the diffusion, while those in the middle and bottom will not achieve the same income success.

Income inequality becomes difficult to measure because there are so many factors - political, social, technological, etc. I tried to isolate the social and technological by focusing on infrastructure use and diffusion. While some countries increase income inequality over time for infrastructure growth (i.e., the past twenty years), most countries have reduced income inequality over this time. As such, I will focus on a few countries with vastly different political, social, and technological statuses with differing levels of the diffusion to income inequality relationship - Iceland, Ghana, and the United States.

Iceland provides a model for success of diffusion of Internet infrastructures. 84\% of Iceland households received Internet access in 2005, and in 2018 was 99\% [28]. They rank at or near the top for all network readiness factors in the Global Information Technology Report. Many countries lag behind in rural Internet access, but the Iceland government engages with rural areas and Internet Service Providers (ISPs) to enable access. Meanwhile, Iceland also ranks first in income distribution in our dataset. They achieve this success through a combination of capitalist structure and free market principles combined with an extensive welfare system [29].

Ghana gives a different view of the relationships because it is a developing country. Ghana, like many developing countries, experience low levels of infrastructure diffusion. Their infrastructure according to the Global IT Report ranks number 99 out of 111 countries. Approximately 13\% of individuals have broadband access [30]. Meanwhile, their income inequality is in the middle, ranked 54.

Gini data can differ depending on source - such as the World Bank, World Economic Forum, etc. - as they all use different methodologies. Internet diffusion data may also differ by source. These inconsistencies make it difficult to find consistent data over a time series. To view the relation of income inequality and diffusion, I charted income inequality data with Internet penetration data from the World Bank. See figure 2, 3, and 4. In each chart, the $y$-axis on the left indicates Gini and the y-axis on the right indicates Internet penetration percentage.

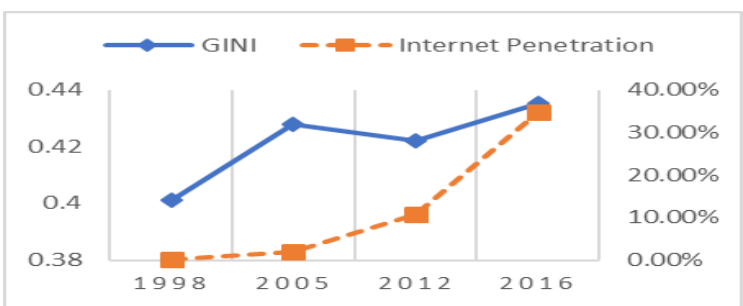

Figure 2. Relationship of Gini to Internet Penetration in Ghana, 1998-2016 


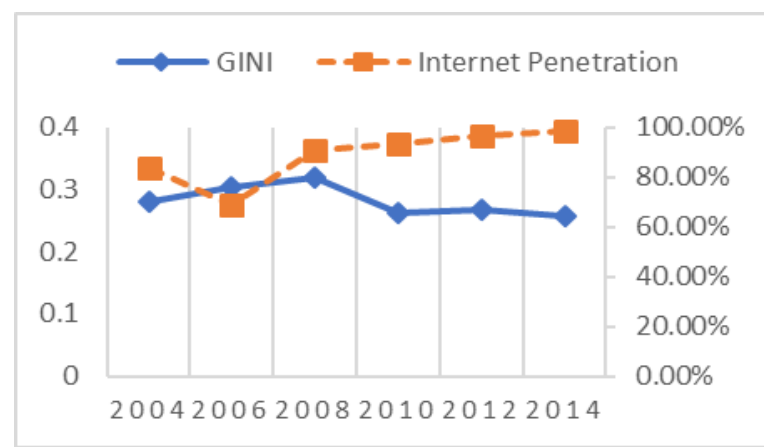

Figure 3. Relationship of Gini to Internet Penetration in Iceland, 2004-2014

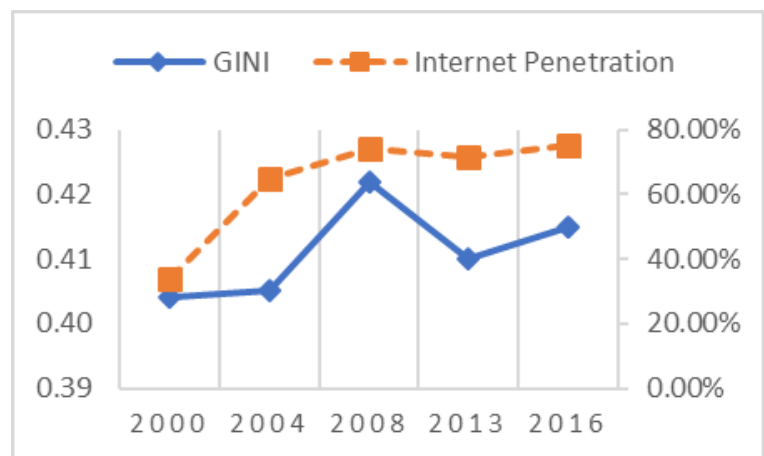

Figure 4. Relationship of Gini to Internet Penetration in the US, 2000-2016

The three charts show a few things regarding the relationship of inequality and Internet diffusion. DOI identifies a curve over time that starts slow, rises sharply during the middle of the diffusion, then flattens as adoption nears the end. Iceland and the US display a similar curve regarding Internet penetration. Ghana experienced moderate growth from 2005 to 2012, then a sharp increase in growth to 2016, probably due to the diffusion of mobile phones. It will be interesting to see the growth trend over the next few years whether it flattens or remains strong.

Second, the shape between Gini and Internet penetration show completely different patterns for each of the three countries. In Ghana, the ratio of Gini to penetration was skewed toward higher Gini. In 2016, that ratio was smaller, with Gini growing slightly and Internet penetration growing sharply. Iceland's relation looks completely different. Gini has decreased slightly, while Internet penetration has steadily grown. On the near end of the chart, I observe a slight divergence between penetration and Gini.

With Iceland's penetration at nearly $100 \%$, it will be interesting to see how Gini changes over the coming years. The infrastructure investments, regulations, and competition are more mature than nearly any other country, so Iceland will be doing maintenance and upgrades instead of initial implementation. This may affect many things such as jobs and suppressing new infrastructure market entrants. Iceland is not unique with strong Gini and Internet use. Scandinavian countries, such as Sweden, Finland, and Norway, are among the top countries.

The US experiences a different looking chart as well, which may reflect the economic environment in the country. In the great recession of 2008, I observe a sharp growth in income inequality, with a slight uptick in Internet penetration. Both Gini and penetration dropped slightly following the recession, although both appear on similar paths through 2016. In summary, the charts show three different paths for each country with the relationship of income inequality to Internet diffusion - Ghana experiences a convergence, Iceland a divergence, and the United States appears near parallel.

\section{Within the United States}

Interestingly, Internet use in the US has fluctuated over the last two decades. Internet penetration in 2000 was only $43.08 \%$, rising steadily to $75 \%$ in 2007 , steadily falling to $69.73 \%$ in 2011 , and then growing steadily to $75.23 \%$ in 2017 [31] (see Figure 4). During this time, Gini experienced sharp changes, but over time remained consistent, as discussed in the previous subsection.

Most other countries see an improvement of income inequality through Internet diffusion. However, the US does not experience this improvement. Among US states, there is also not a significant relationship, although region is a significant predictor of this relationship. As such, this subsection will focus first on a few states, and second on regions. The broadband statistics for this section come from the BroadbandNow initiative [32], unless otherwise noted.

The discussion on states will focus on three states with differing inequality and infrastructure outcomes, and from different regions. Pennsylvania ranks 29 in both infrastructure and inequality. Pennsylvania is located in the east region, with a Gini of .469 and Internet penetration of $78.2 \%$. As a state in the middle of the national average in both these categories, Pennsylvania recognized their middling infrastructure and 650,000 residents who lack highspeed Internet access, as Governor Tom Wolf launched a "Broadband Initiative," dedicated to 
providing high-speed Internet access to all households and businesses in Pennsylvania [33]. Over the next few years it will be interesting to see how inequality and infrastructure changes in Pennsylvania.

South Dakota ranks 43 in infrastructure and 8 in inequality (35 places worse in infrastructure, the largest difference for infrastructure minus inequality). South Dakota is located in the midwest region, with a Gini of .444 and Internet penetration of $79 \%$. Their income equality is one of their strengths as a state, although compared to countries, their inequality is still poor. In 2010, South Dakota received nearly $\$ 6,000,000$ in federal grants on a broadband initiative - since then, their wired connections of at least 10 megabit per second improved from $71.1 \%$ to $93.9 \%$. Despite this, South Dakota still experiences challenges to Internet adoption.

California ranks 13 in infrastructure and 47 in inequality (34 places worse in inequality, the largest difference for inequality minus infrastructure). California is located in the west region, with a Gini of .488 and Internet penetration of $83.8 \%$. California contains a mix of urban and rural, with many startups and technology hubs on the coast, and farming in the central inland valleys. California has received $10 \%$ of all federal infrastructure grants, at approximately $\$ 350$ million. Unfortunately, this federal funding has not had a positive impact on income inequality in California.

When looking at the data by region, the relationship between Internet penetration and Gini becomes clear. See Figure 5 for the average Gini and average Internet penetration.

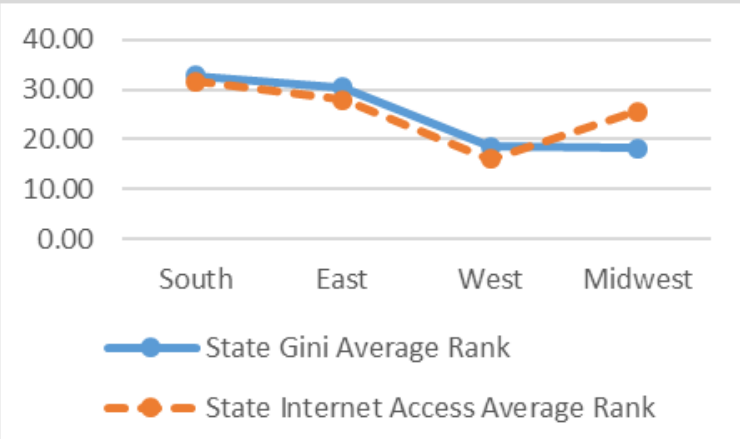

Figure 5. Average Gini and Internet Penetration Ranks by Region

The south and east regions experience higher income inequality and have less infrastructure diffusion. The west and midwest have lower income inequality and greater infrastructure diffusion. The relationship between infrastructure and inequality appears congruent in the south, east, and west, while the midwest may experience the opposite relationship.

\section{Conclusions}

To conclude, I will identify limitations of this study, future research and opportunities, and summarize the key contributions. One limitation of this study is with the nature of the data. Gini calculations and infrastructure measures differ depending on the source. Annual data also can be inconsistent. For instance, the World Bank contained data every two years between 2004 and 2014 for Iceland on Gini and Internet penetration. Their data on the US comes from 2000, 2004, 2008, 2013, and 2016. This inconsistency becomes difficult to compare countries at the same level. Second, income inequality deals with an incredible number of factors. This makes it difficult to isolate a single factor or series of factors - be it economic, technology, regulatory, etc. Third, this study does not take into account whether the country is developing or developed.

These limitations offer fruitful opportunities for future research. First, researchers from multiple disciplines - economics, sociology, political science, IS, etc. - can work together to isolate and identify factors related to income inequality. Economics researchers are not experts in IS use, IS researchers are not experts in economic principles, and a multidisciplinary study may be necessary. Second, researchers may employ a case study methodology to understand successful countries and states and compare them to unsuccessful countries and states regarding income inequality. Researchers should conduct such a study longitudinally, to view the changes in Internet diffusion and income inequality over time. Third, The WEF separates developed and developing countries into the type of economy advanced or emerging [26]. Advanced economies typically have lower inequality and stronger infrastructures. Researchers can measure whether DOI holds when separating countries by the type of economy.

This study found mixed results regarding Internet diffusion and its relationship with income inequality and offers many practical and research contributions. First, a contribution to practice is for governments and industries to use Iceland and other similar countries as a model. Research shows how lower 
income inequality leads to the well-being of its citizens; Iceland's blend of government investment and regulation, free market competition, and infrastructure investment may show other locations how to improve infrastructure while also improving the well-being of its citizens. ISPs typically only invest in infrastructure if they see a strong potential return on their investment. This practice limits Internet in rural areas, developing countries, poor states, etc. It also may negatively affect job growth and opportunities for citizens. I urge governments to create subsidies to promote infrastructure development, such as South Dakota's federal grant funding, while also providing economic incentives to citizens. Federal subsidies should include more equal distribution, as $10 \%$ of federal funding goes to California, with fewer federal subsidies in the south.

User acceptance appears to be a key factor in improving inequality regarding Internet infrastructure. DOI focuses on the five factors of relative advantage, compatibility, complexity, observability, and trialability. If individuals do not see the advantage of a technology, are unable to use a technology due to lack of knowledge or owning a computer, they may not adopt Internet technologies. With Iceland's penetration at $99 \%$, they have adopted the Internet at a societal level, which has decreased income inequality, which in turn improves the wellbeing of individuals. The factors of affordability, business innovation, individual usage, and infrastructure have the potential to decrease income inequality. In the US, non-government organizations may be able to help by developing training programs, refurbishing old computers for those less fortunate, and applying for federal funding to support these programs.

This study contributes to research by exploring the effects of Internet diffusion on income inequality. Most research on these relationships comes from sociology and economics, but IS can be an important discipline in these phenomena as well. Second, this research found the tenets of DOI regarding the relationship between technology diffusion and income inequality do not hold regarding Internet infrastructure and use. Diffusion of Internet infrastructure has a positive effect on income inequality - as such, researchers can extend this research to understand the factors positively affecting income inequality. Third, even though the United States has high Internet diffusion, income inequality is also high. Researchers can focus on the local level such as state governments, ISP investments, etc. Moreover, diffusion and inequality differ by region, so researchers can explore the underlying factors for each region in the US. Last, researchers can improve the quality of the data regarding Internet diffusion and inequality. As described in the data analysis plan, data for this study comes from multiple sources. Because this study explores the relationship between technology and inequality, and ultimately to individual well-being, researchers may be able to seek grant funding to improve the quality of data for understanding these phenomena.

Returning to the genesis of this study, Manoush and her colleagues' observation holds true in California, as they experience incredible inequality despite having tremendous access to benefits of the Internet. Globally, this relationship is untrue. I encourage researchers to expand on this study to learn more about the underlying factors of inequality, thus potentially increasing the well-being of both local and global citizens.

\section{References}

[1] Zomorodi, M., "Zigzag Chapter 4: Hedging Your Bets", Stable Genius Productions. https://zigzagpod.com/2018/06/28/hedging-your-bets/, accessed May 30, 2019.

[2] Gonzales, A., "The Contemporary Us Digital Divide: From Initial Access to Technology Maintenance", Information, Communication \& Society, 19(2), 2016, pp. 234-248.

[3] Berube, A., and Holmes, N., "City and Metropolitan Inequality on the Rise, Driven by Declining Incomes", Brookings Institution, 2016, pp. 1-13.

[4] Rogers, E.M., Diffusion of Innovations, Free Press, 4th edn, New York, 1995.

[5] Rogers, E.M., Diffusion of Innovations, Free Press, 5th edn, New York, 2003.

[6] Cozzens, S., and Thakur, D., Innovation and Inequality: Emerging Technologies in an Unequal World, Edward Elgar Publishing, 2014.

[7] Park, S., and Yoon, S.-H., "Separating Early-Adopters from the Majority: The Case of Broadband Internet Access in Korea", Technological Forecasting and Social Change, 72(3), 2005, pp. 301-325.

[8] Moore, G.C., and Benbasat, I., "Development of an Instrument to Measure the Perceptions of Adopting an Information Technology Innovation", Information Systems Research, 2(3), 1991, pp. 192-222. 
[9] Venkatesh, V., Morris, M.G., Davis, G.B., and Davis, F.D., "User Acceptance of Information Technology: Toward a Unified View", MIS Quarterly, 27(3), 2003, pp. 425-478.

[10] Kim, D., and Ammeter, T., "Predicting Personal Information System Adoption Using an Integrated Diffusion Model", Information \& Management, 51(4), 2014, pp. 451-464.

[11] Bradford, M., and Florin, J., "Examining the Role of Innovation Diffusion Factors on the Implementation Success of Enterprise Resource Planning Systems", International Journal of Accounting Information Systems, 4(3), 2003, pp. 205-225.

[12] Beatty, R.C., Shim, J.P., and Jones, M.C., "Factors Influencing Corporate Web Site Adoption: A Time-Based Assessment", Information \& Management, 38(6), 2001, pp. 337-354.

[13] Premkumar, G., Ramamurthy, K., and Nilakanta, S., "Implementation of Electronic Data Interchange: An Innovation Diffusion Perspective", Journal of Management Information Systems, 11(2), 1994, pp. 157-186.

[14] Miranda, S.M., Kim, I., and Summers, J.D., "Jamming with Social Media: How Cognitive Structuring of Organizing Vision Facets Affects IT Innovation Diffusion", MIS Quarterly, 39(3), 2015, pp. 591-614.

[15] Jones, C.I., and Kim, J., "A Schumpeterian Model of Top Income Inequality", Journal of Political Economy, 126(5), 2018, pp. 1785-1826.

[16] Lohmann, S., "Information Technologies and Subjective Well-Being: Does the Internet Raise Material Aspirations?", Oxford Economic Papers-New Series, 67(3), 2015, pp. 740-759.

[17] Panizza, U., "Income Inequality and Economic Growth: Evidence from American Data", Journal of Economic Growth, 7(1), 2002, pp. 25-41.

[18] Shin, I., "Income Inequality and Economic Growth", Economic Modelling, 29(5), 2012, pp. 2049-2057.

[19] Guzman, G., "Household Income: 2016: American Community Survey Briefs", https://www.census.gov/content/dam/Census/library/public ations/2017/acs/acsbr16-02.pdf, accessed June 10, 2019.

[20] Bank, W., Poverty and Shared Prosperity 2016: Taking on Inequality, World Bank, Washington, DC, 2016.

[21] Aghion, P., Akcigit, U., Bergeaud, A., Blundell, R., and Hémous, D., "Innovation and Top Income Inequality", The Review of Economic Studies, 86(1), 2018, pp. 1-45.
[22] Bakija, J., Cole, A., and Heim, B.T., "Jobs and Income Growth of Top Earners and the Causes of Changing Income Inequality: Evidence from Us Tax Return Data", Department of Economics Working Papers, Williams College, 2012, pp. 1-78.

[23] Richmond, K., and Triplett, R.E., "Ict and Income Inequality: A Cross-National Perspective", International Review of Applied Economics, 32(2), 2018, pp. 195-214.

[24] Sarma, M., and Pais, J., "Financial Inclusion and Development", Journal of International Development, 23(5), 2011, pp. 613-628.

[25] Baller, S., Dutta, S., and Lanvin, B., Global Information Technology Report 2016, Ouranos Geneva, 2016.

[26] "The Inclusive Development Index 2018", World Economic Forum. http://www3.weforum.org/docs/WEF_Forum_IncGrwth_20 18.pdf, accessed June 11, 2019.

[27] "Infrastructure Rankings", U.S. News \& World Report. https://www.usnews.com/news/beststates/rankings/infrastructure, accessed June 11, 2019.

[28] "Share of Households with Internet Access in Iceland from 2005 to 2014", Eurostat. https://www.statista.com/statistics/377769/householdinternet-access-in-iceland/, accessed June 11, 2019.

[29] "Best Countries for Business", Forbes. https://www.forbes.com/places/iceland/, accessed June 13, 2019.

[30] Itu, G., "Mobile and Fixed Broadband Penetration in Africa by Country in 2015", Statista - The Statistics Portal. https://www.statista.com/statistics/220717/fixed-andmobile-broadband-penetration-in-africa-by-country/, accessed June 11, 2019.

[31] Bureau, U.C., "Percentage of Population Using the Internet in the United States from 2000 to 2017", Statista The Statistics Portal.

https://www.statista.com/statistics/209117/us-internetpenetration/, accessed June 12, 2019.

[32] Anderson, D., and Reese, N., "Broadbandnow", https://broadbandnow.com, accessed June 14, 2019.

[33] Wolf, T., "Pennsylvania Broadband Initiative", https://www.governor.pa.gov/about/broadband, accessed June 14, 2019. 